DOI: 10.36910/6775-2524-0560-2019-37-10

УДК: 515.2

Ісмаілова Н. П., Елісєєв І. М.

Військова академія (м. Одеса)

\title{
МОДЕЛЮВАННЯ СПРЯЖЕНИХ ПОВЕРХОНЬ ЗА ДОПОМОГОЮ МЕТОДА КРУГОВОГО ПЕРЕТВОРЕННЯ В СИСТЕМЕ МАТLАВ
}

Ісмаілова Н. П., Елісєєв І. М. Моделювання спряжених поверхонь за допомогою метода кругового перетворення в системе MATLAB. Запропоновано комп'ютерне моделювання спряжених поверхонь еліптичний параболоїд і осі - конічна гвинтова лінія в системі MATLAB.

Ключові слова: спряжені поверхні, еліптичний параболоїд, конічна гвинтова лінія, система MATLAB.

Исмаилова Н. П., Елисеев И. М. Моделирование сопряженных поверхностей с помощью метода кругового преобразования в системе МАTLAB. Предложено компьютерное моделирование сопряженных поверхностейэллиптичный параболоид и оси - коническая винтовая линия в системе MATLAB. система MATLAB.

Ключові слова; сопряженные поверхности, эллиптический параболоид, коническая винтовая линия,

N. Ismailova , I. Eliseev. Modeling conjugate surfaces using the circular transformation method in the MATLAB system. Computer simulation of mating surfaces is proposed - an elliptical paraboloid and axes - a conical helix in the MATLAB system.

Keywords: mating surfaces, elliptical paraboloid, conical helix, MATLAB system.

Постановка наукової проблеми. Одне з основних напрямків нарисної геометрії - формування складних спряжених поверхонь - нерозривно пов'язане зі всіма галузями і видами виробництва [1].

Комп'ютерне геометричне моделювання складних спряжених поверхонь підвищує продуктивність розрахунково-конструкторських робіт.

Аналіз досліджсень. Комп'ютерне моделювання спряжених поверхонь деталей в машинобудуванні складної форми вирішує проблему підвищення точності профілювання та продуктивності праці конструктора. Метою даного дослідження $є$ розробка комп моделювання за допомогою метода кругового перетворення в системі MATLAB, спряжених поверхонь деталей в машинобудуванні.

Основна частина. Розглянемо реалізацію методу кругового перетворення стосовно поверхні - еліптичний параболоїд, заданий параметричних рівнянням (1) і осі - конічна гвинтова лінія, задана параметричних рівнянням (2).

$$
\left\{\begin{array}{c}
x=a \cdot u \cdot \cos v \\
y=b \cdot u \cdot \sin v \\
z=0.5 \cdot u^{2}
\end{array}\right.
$$

где $0 \leq u \leq 5,0 \leq v \leq \pi, a=3, b=2$

$$
\begin{gathered}
\left\{\begin{array}{l}
x=t \cdot \sin t \\
y=t \cdot \cos t, \\
z=c \cdot t
\end{array}\right. \\
\text { где } c=\frac{H}{2 \cdot \pi}, 0 \leq t \leq 2 \pi, H=5
\end{gathered}
$$

Побудова поверхні і криволінійної осі в системі MATLAB наведено нижче:

\% Завдання параметрів еліптичного параболоїда

ap $=3$;

$\mathrm{bp}=2$;

up $=(0: 0.05: 5)^{\prime}$;

$\mathrm{vp}=\left[0: 0.05^{*}\right.$ pi:pi $]$; 
$\mathrm{Xp}=\mathrm{ap} * \mathrm{up} * \cos (\mathrm{vp})$

$\mathrm{Yp}=\mathrm{bp} * \mathrm{up} * \sin (\mathrm{vp})$

$\mathrm{Zp}=0.5 *$ up. ${ }^{\wedge} 2 *$ ones $(\operatorname{size}(\mathrm{vp}))$;

$\%$ Завдання параметрів конічної гвинтової лінії

$\mathrm{Hv}=15$;

$\mathrm{cv}=\mathrm{Hv} /(2 * \mathrm{pi})$;

tv $=0:$ pi $/ 50: 2 *$ pi;

$\mathrm{Xv}=\mathrm{tv} . * \sin (\mathrm{tv})$

$\mathrm{Yv}=\mathrm{tv} . * \cos (\mathrm{tv})$;

$\mathrm{Zv}=\mathrm{tv} \cdot * \mathrm{cv}$;

\% Висновок на екран еліптичного параболоїда і конічної гвинтової лінії в цьому ж вікні figure('Color','w')

$\mathrm{ElPar}=\operatorname{mesh}(\mathrm{Xp}, \mathrm{Yp}, \mathrm{Zp})$;

xlabel('x'); ylabel('y'); zlabel('z')

hold on

KonVin=plot3(Xv, Yv,Zv);

grid on

Результат побудови показаний на ріс.1-4.

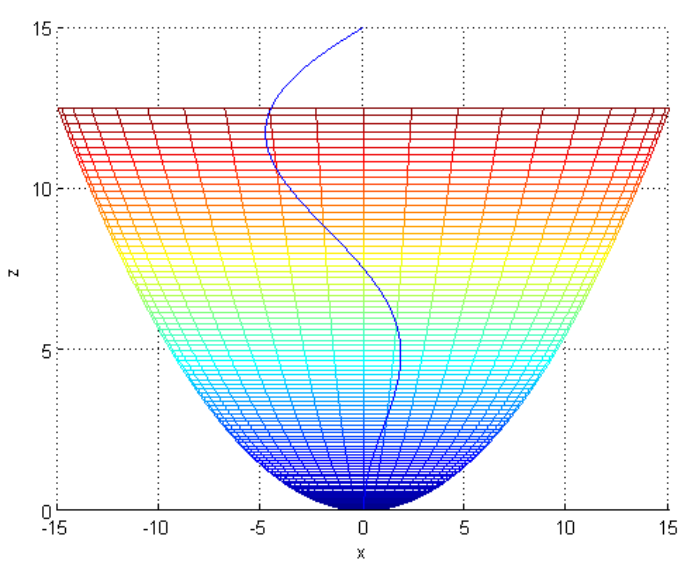

Рис.1. Проекція на площину $\mathrm{XZ}$

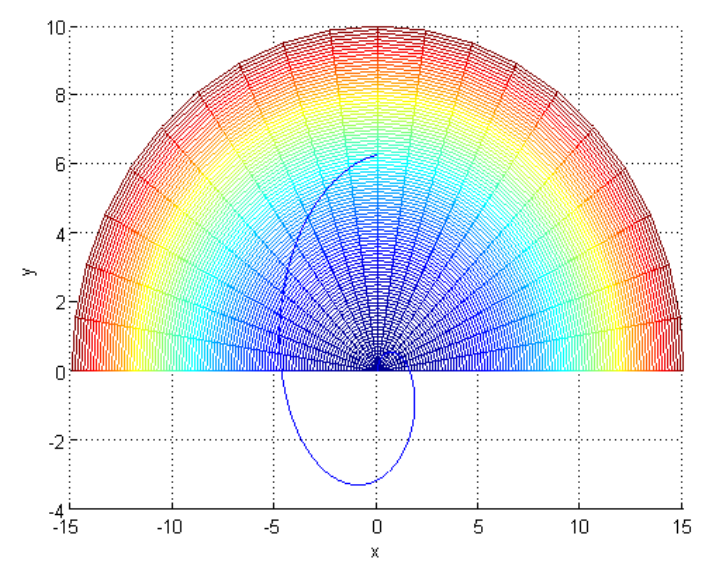

Рис.3. Проекція на площину XY

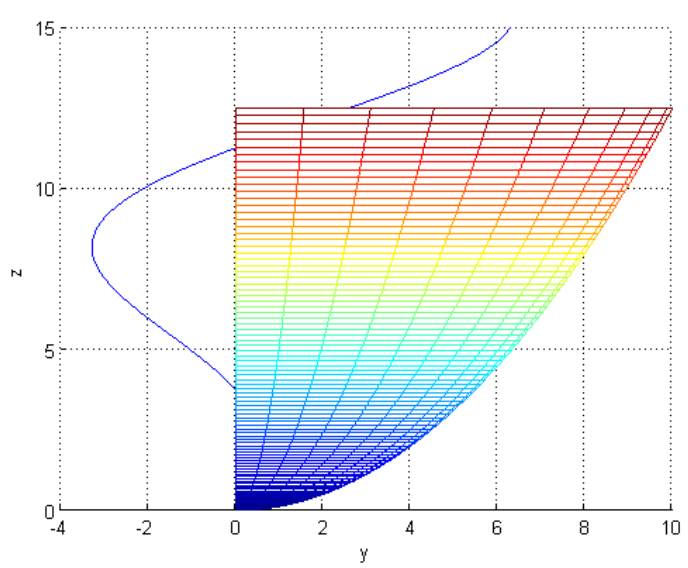

Рис.2. Проекція на площину YZ

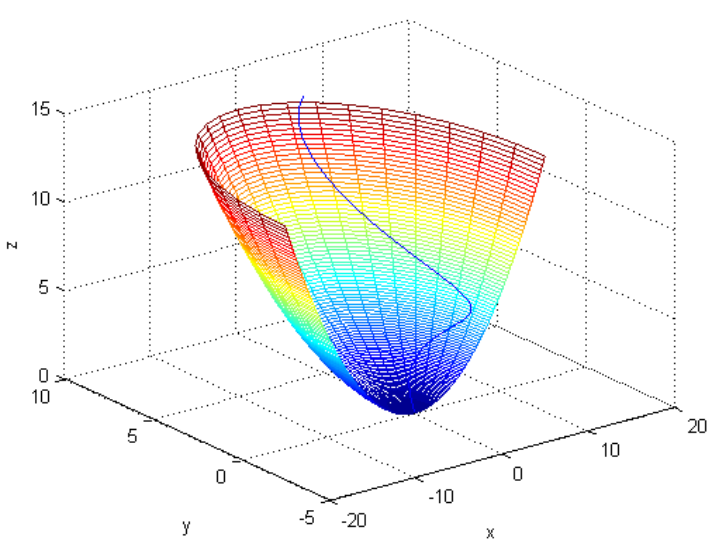

Рис.4. Тривимірне представлення 
Зрушимо криволінійну вісь на відстань -25 по осі Y, 5 по осі X i -2 по осі Z. Параметричне рівняння конічної гвинтової лінії набуде вигляду (3).

$$
\begin{gathered}
\left\{\begin{array}{l}
x=x_{0}+t \cdot \sin t \\
y=y_{0}+t \cdot \cos t, \\
z=z_{0}+c \cdot t
\end{array}\right. \\
\text { где } c=\frac{H}{2 \cdot \pi}, 0 \leq t \leq 2 \pi, H=5, x_{0}=5, y_{0}=-25, z_{0}=-2
\end{gathered}
$$

Змінивши синтаксис побудови, наведений нижче, отримаємо результат, показаний на pic.5-8. $\%$ Завдання параметрів еліптичного параболоїда

ap=3;

$\mathrm{bp}=2$;

up $=(0: 0.05: 5)^{\prime}$

$\mathrm{vp}=\left[0: 0.05^{*}\right.$ pi:pi $]$;

$\mathrm{Xp}=\mathrm{ap}^{*} \mathrm{up} * \cos (\mathrm{vp})$;

$\mathrm{Yp}=\mathrm{bp} * \mathrm{up} * \sin (\mathrm{vp})$

$\mathrm{Zp}=0.5^{*}$ up..$^{\wedge}{ }^{*}$ ones(size(vp));

$\%$ Завдання параметрів конічної гвинтової лінії

$\mathrm{Hv}=15$;

$\mathrm{cv}=\mathrm{Hv} /(2 * \mathrm{pi})$;

$\mathrm{x} 0 \mathrm{v}=5$;

$\mathrm{y} 0 \mathrm{v}=-25$;

$\mathrm{z} 0 \mathrm{v}=-2$;

$\mathrm{tv}=0: \mathrm{pi} / 50: 2 * \mathrm{pi}$

$\mathrm{Xv}=\mathrm{x} 0 \mathrm{v}+\mathrm{tv} \cdot * \sin (\mathrm{tv})$

$\mathrm{Yv}=\mathrm{y} 0 \mathrm{v}+\mathrm{tv} \cdot * \cos (\mathrm{tv})$

$\mathrm{Zv}=\mathrm{Z} 0 \mathrm{v}+\mathrm{tv} . * \mathrm{cv}$

\% Висновок на екран еліптичного параболоїда і конічної гвинтової лінії в цьому ж вікні figure('Color','w')

ElPar $=\operatorname{mesh}(\mathrm{Xp}, \mathrm{Yp}, \mathrm{Zp})$;

xlabel('x'); ylabel('y'); zlabel('z')

hold on

KonVin=plot3(Xv, Yv,Zv);

grid on

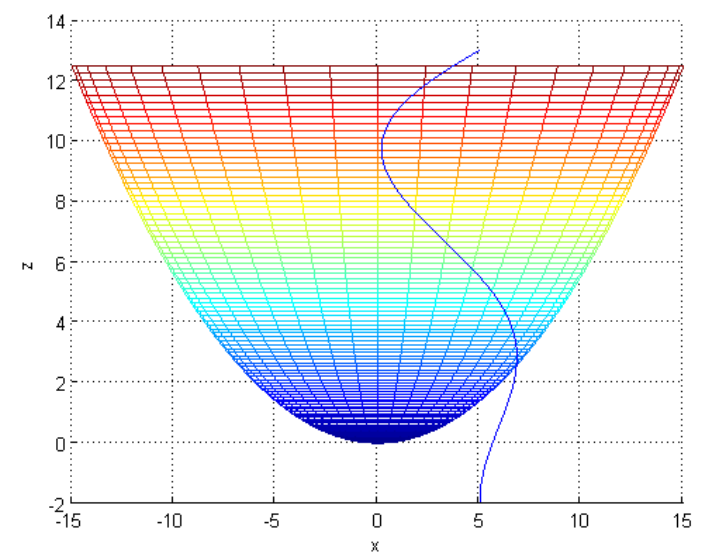

Рис.5. Проекція на площину XZ

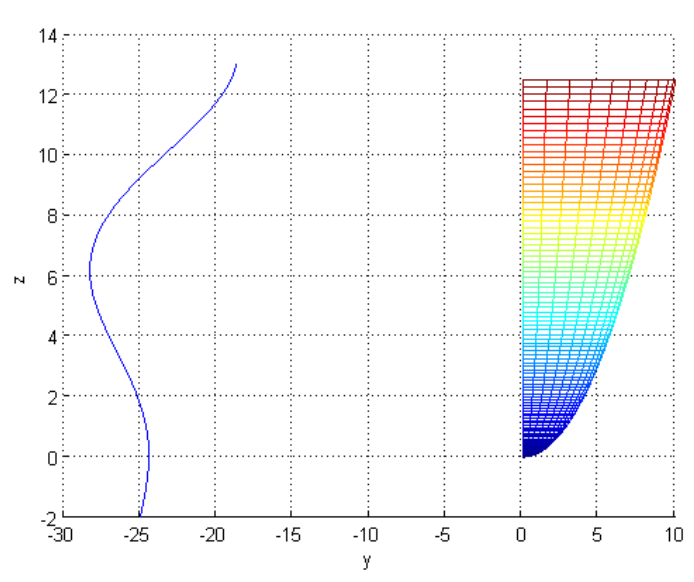

Рис.6. Проекція на площину YZ 


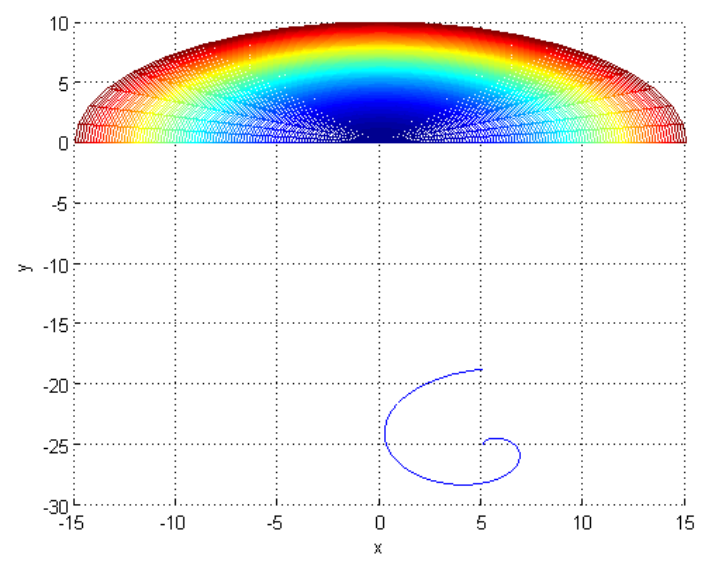

Рис.7. Проекція на площину XY

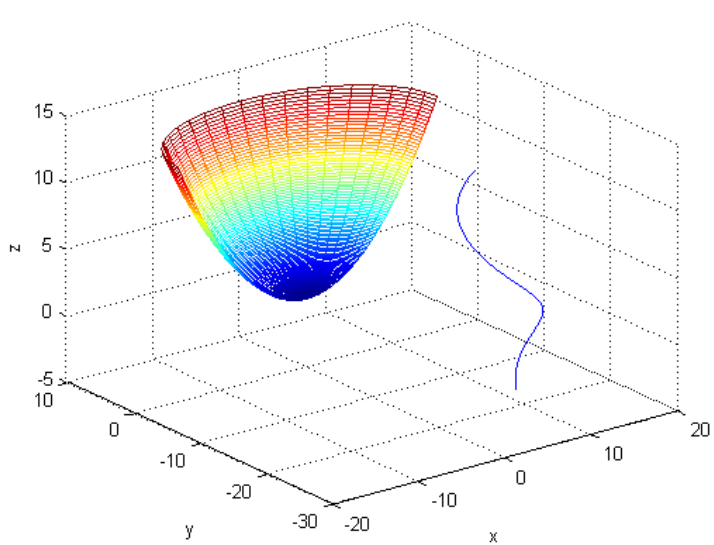

Рис.8. Тривимірне представлення

Визначимо максимальне і мінімальне значення z для криволінійної поверхні.

$\operatorname{miP}=\min (Z p)$;

$\min Z \mathrm{p}=\operatorname{miP}(1)$

$\operatorname{maP}=\max (\mathrm{Zp})$;

$\max Z \mathrm{p}=\operatorname{maP}(1)$;

Побудовано лінії рівня для криволінійної поверхні.

[ur] $=[\operatorname{minZp}: 0.1: \operatorname{maxZp}]$

hold on

[contEP, hEP]=contour3(Xp, Yp, Zp, ur);

Определена длина массива ur.

lenUr=length(ur);

Визначимо точки перетину конічної гвинтової лінії з горизонтальними площинами,

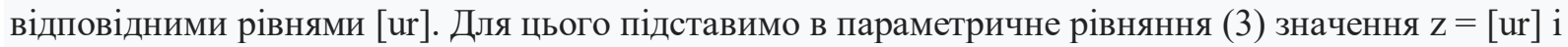
обчислимо значення хрр і урр.

$$
\begin{aligned}
& {[\mathrm{t} 0]=([\mathrm{ur}]-\mathrm{z} 0 \mathrm{v}) / \mathrm{cv} ;} \\
& \mathrm{xpp}=\mathrm{x} 0 \mathrm{v}+\sin (\mathrm{t} 0) . * \mathrm{t} 0 ; \\
& \mathrm{yp}=\mathrm{y} 0 \mathrm{v}+\cos (\mathrm{t} 0) . * \mathrm{t} 0 ;
\end{aligned}
$$

Повернемо кожну лінію рівня на кут $60^{\circ}$ навколо відповідної точки перетину криволінійної осі щодо осі Z. Для цього створимо функцію Rotate Different Center( lines, $x C, y C$, zC, length, angle ), де lines - набір ліній рівня, $x C, y C, z C$ - координати точок перетину криволінійної осі 3 горизонтальною площиною рівня, length - довжина масиву, angle - кут повороту.

function Rotate Different Center( lines, $\mathrm{xC}, \mathrm{yC}, \mathrm{zC}$, length, angle )

for $\mathrm{i}=1$ :length

rotate(lines(i), [0 00 1], angle, [xC(i) yC(i) zC(i)])

end

end

У вікні Command Window викликана створена функція повороту.

RotateDifferentCenter(hEP,xpp,ypp,ur,lenUr,60)

Результат перетворення показаний на рис.9-14. 


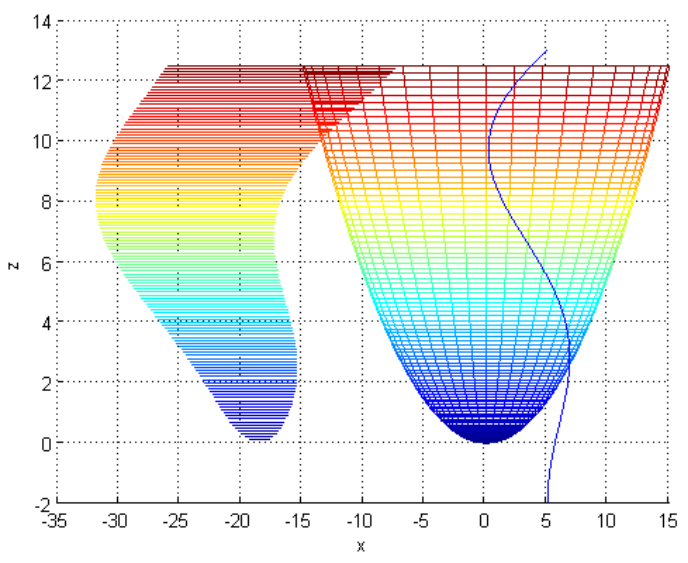

Рис.9. Проекція на площину XZ

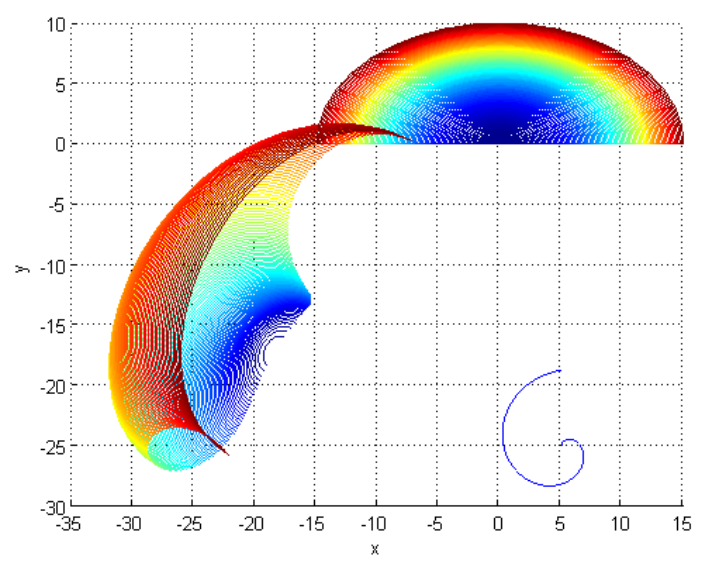

Рис.11. Проекція на площину XY

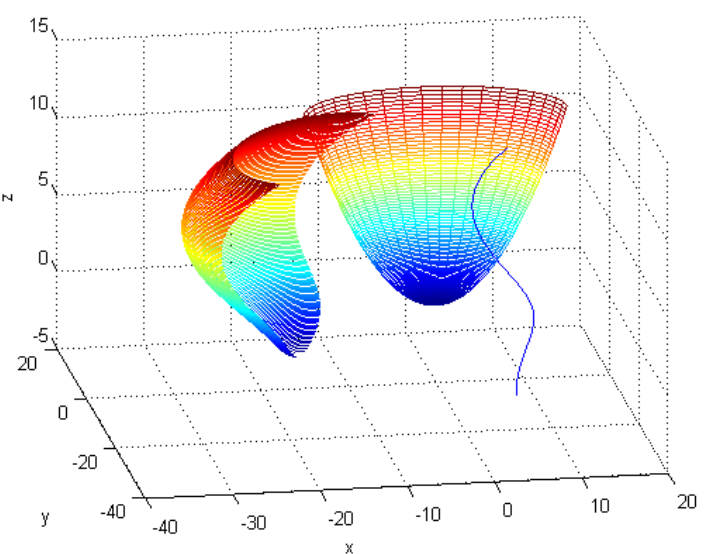

Рис.13. Тривимірне представлення

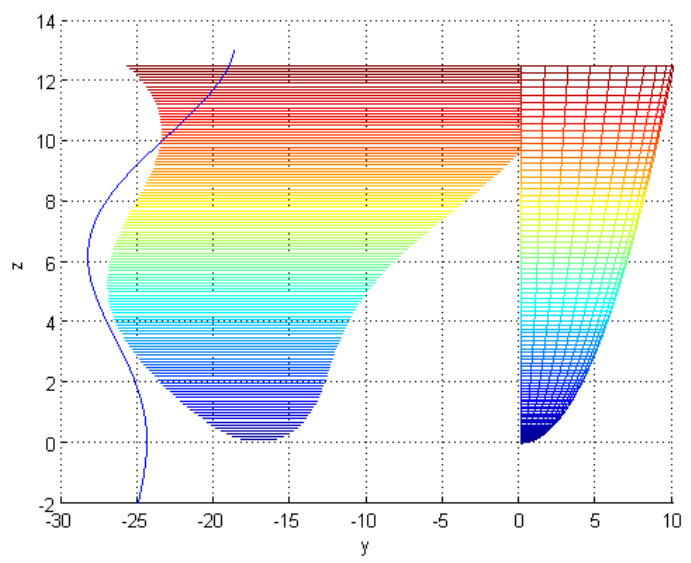

Рис.10. Проекція на площину YZ

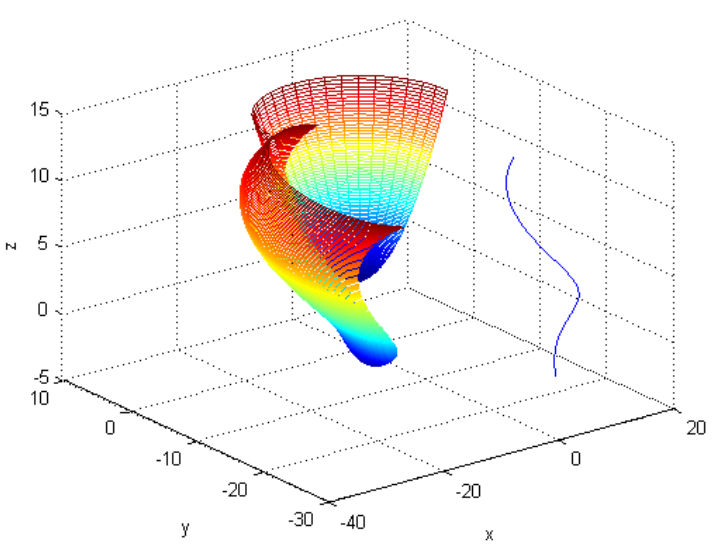

Рис.12. Тривимірне представлення

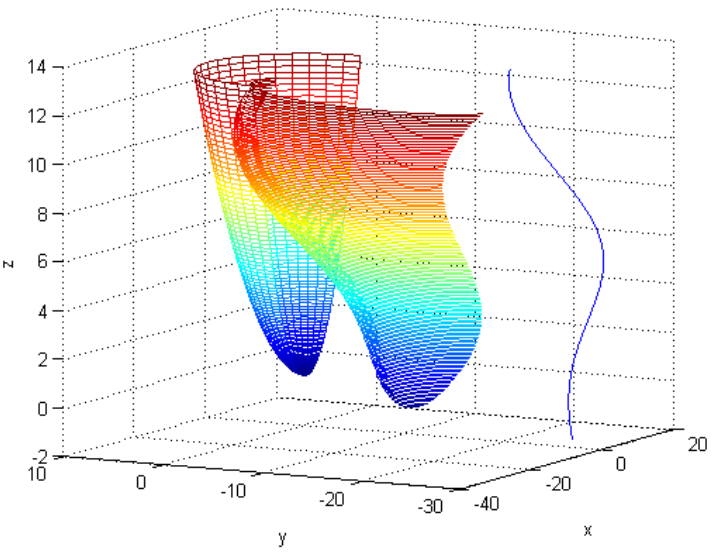

Рис.14. Тривимірне представлення

У цей час, практично всі проектні рішення виконуються за допомогою САПР. Це дозволяє істотно скоротити час на проектування. Але не завжди за допомогою стандартних засобів комп'ютерного моделювання можна вирішити поставлене завдання. У зв'язку із цим виникає необхідність у створенні спеціальних підпрограм для побудови методів проектування спряжених поверхонь, тому що в них $є$ криволінійні й напрямна, і утворююча.

Розроблений геометричний метода кругового перетворення за допомогою комп'ютерного моделювання дозволяє вирішить складні завдання конструювання спряжених поверхонь, підвищити точність i продуктивність інженерної праці i створювати конкурентно-здатні вироби в машинобудуванні, літакобудуванні, кораблебудуванні. 
Висновки та перспективи подальшого дослідження. У результаті проведених досліджень ми розробили підпрограму для визначення кругового перетворення спряжених поверхонь до рішення проблеми конструкторських робіт в машинобудуванні яка має можливість підвищення точності профілювання та продуктивності. Подальші дослідження які розроблені у напрямі розробки кругового перетворення спряжених поверхонь розширення побудови спряжених поверхонь, також наблизиться до вирішення проблеми виключення інтерференції при профілювання деталей в машинобудуванні.

\section{Список бібліографічного опису.}

1. Подкоритов А.Н., Исмаилова Н.П., Дюкре Л.Г. Метод формирования сопряженных винтовых нелинейчатых поверхностей семейством огибающих геликоидов. Геометричне та комп'ютерне моделювання. - Вип..17. ХДУХТ. - Харків, 2007. - С.12-15.

2. Ісмаілова Н. П. Твердотільне моделювання спряжених поверхонь на базі параметричного кінематичного гвинта [Текст] /Ісмаілова Н. П. Комп’ютерно-інтегровані технології: освіта, наука, виробництво. - Луцьк, 2015. - С. 69-74.

3. Ісмаілова Н.П., Трушков Г.В. Геометричне моделювання просторового параметричного кінематичного гвинта/ Комп'ютерно-інтегровані технології: освіта, наука, виробництво. Луцький національний технічний університет. Науковий журнал. №30-31 2018. Луцк - 2018. С. 187-195

\section{References}

1. Podkoritov A.N, Ismailova N.P, Ducret LG Method of forming conjugate helical nonlinear surfaces by a family of envelope helicoids. Geometric and computer modeling. - Issue 17. - CDHD. - Kharkiv, 2007. - P.12-15.

2. Ismailova N.P Solid state modeling of conjugate surfaces based on parametric kinematic screw [Text] / Ismailova NP Computer-integrated technologies: education, science, production. Lutsk, 2015, pp. 69-74.

3. Ismailova N.P, Trushkov G.V Geometric modeling of spatial parametric kinematic screw /Computer-integrated technologies: education, science, production. Lutsk National Technical University.Scientific journal. №30-31 2018. Lutsk - 2018. P. 187-195 